Research Article

\title{
Gearbox Low-Noise Design Method Based on Panel Acoustic Contribution
}

\author{
Jianxing Zhou, Wenlei Sun, and Qing Tao \\ School of Mechanical Engineering, Xinjiang University, Urumqi 830047, China \\ Correspondence should be addressed to Jianxing Zhou; jianzhou82923@163.com
}

Received 15 September 2013; Accepted 28 November 2013; Published 2 January 2014

Academic Editor: Hamid Reza Karimi

Copyright (C) 2014 Jianxing Zhou et al. This is an open access article distributed under the Creative Commons Attribution License, which permits unrestricted use, distribution, and reproduction in any medium, provided the original work is properly cited.

\begin{abstract}
This paper presents a comprehensive procedure to calculate steady dynamic response and generated noise radiation from a gear reducer. In this process, the dynamic model of the cylindrical gear transmission system is built in consideration of the timevarying mesh stiffness, gear errors, and bearing supporting, while the data of dynamic bearing force is obtained through solving the model. Furthermore, taking the data of bearing force as the excitation, the gearbox vibrations and noise radiation are calculated by numerical simulation, and then the time history of node dynamic response, noise spectrum, and resonance frequency range of the gearbox are obtained. At last, the gearbox panel acoustic contribution at the resonance frequency range is calculated. According to the conclusions of the gearbox panel acoustic contribution analyses and the mode shapes, two gearbox stiffness improving plans is researched. By contrastive analysis of gearbox noise radiation, the effectiveness of the improving plans are verified. The study provides useful theoretical guideline to the gearbox design.
\end{abstract}

\section{Introduction}

With many advantages, that is, high efficiency, tight structure, stable speed ratio, and so forth, gear train has been widely used in many industrial fields. When the gear reducer is running, the gearbox vibration is generated, due to the effect of the gear pair dynamic mesh force, which not only affects the stability of the transmission system but also generates noise. In addition, excessive noise produced by a reducer causes crew fatigue, strained communication, and possible hearing damage. In order to ensure a quiet, smooth, and safe operation of a gear transmission system, it is necessary to understand mechanisms of the dynamic response and the noise radiation of the gear reducer; meanwhile, their reduction is highly desired.

With increasing demand for quieter gear systems, a large amount of work was reported in the literatures on analyzing the vibration and noise of the gearbox. Abbes et al. built the gearbox vibroacoustic system by using a three-dimensional finite-element (FE) approach, and the acoustic response of the system was evaluated [1]. Velex and Maatar computed the dynamic responses to mesh stiffness variations for numerical gears [2]. Their results showed the impact of mesh stiffness variation on dynamic response and tooth loads. Dion et al. developed an experimental and numerical study of dynamic phenomena involving gear impacts with one loose gear inside an automotive gearbox [3]. Barthod et al. dealt with the rattle noise, caused by the fluctuation of the engine torque under special conditions, which could cause multiple impacts inside the gearbox [4]. Kato et al. simulated the vibration and noise radiation of a single-stage gearbox by combining finite-element (FE) vibration analysis with boundary element noise analysis [5]. The results of this analysis were well agreed with the corresponding measured data. Spur and helical gears were tested in the NASA gear-noise rig to compare the noise produced by different gear designs [6]. The useful conclusions about the effect of the gear design parameters on gearbox radiated noise were got. Choy et al. presented method to predict both the vibration and noise generated by a gear transmission system under normal operation conditions [7], and the application of the method is demonstrated by comparing the numerical and experimental results for the gear noise test rig. Yanyan and Zhen confirmed that the gear pair is the main excitation of the gear reducer and reduced the gearbox noise through matching the precision grade and stiffness of the gears [8]. Kahraman and Blankenship 
investigated contact ratio effects experimentally using a backto-back gearbox rig. The dynamic transmission error (DTE) amplitudes of spur gear pairs with varying contact ratios were measured. The measurements were performed for excitation at and around the torsional natural frequency of the gear pair. The gear mesh frequency was used as a form of torsional excitation, with the limitation that excitation is dependent on rotational speed [9]. Kostić and Ognjanović found that the noise emission of gear units (gearboxes) depends both on the disturbances (gear meshing, bearing operation, etc.) and on the insulating capabilities and modal behavior of the housing. Natural vibrations of the housing walls can be prevented or intensified depending on design parameters [10]. Tuma reviews practical techniques and procedures employed to quiet gearboxes and transmission units [11]. With the complexity of the gearbox structure and the gear excitation, excessive simplification has been made in most of the previous research; meanwhile no effective method to reducing vibration and noise is found.

In this study, we present a comprehensive procedure to predict the noise radiation of the gear reducer. In the procedure, the 4-DOF dynamic model is built, and then taking the bearing force as the excitation, vibrations and noise radiation of the gearbox are researched. According to the results of the panel acoustic contribution analysis on the resonant frequency band of the gearbox and the mode shapes, effective methods to reducing vibration and noise are suggested.

\section{Analysis Procedure of Noise Radiating}

Gear errors and fluctuations in mesh stiffness can cause excitation during gear meshing; this excitation propagates from the gear shafts to the bearing and excites the gearbox and generations reducer noise which is radiated from the surface of the gearbox. In order to concern about both gear transmission system dynamic characteristics and gearbox dynamic characteristics, an excellent prediction method of gearbox noise radiation is proposed.

As illustrated in Figure 1, the developed method consists of three separate steps: dynamic bearing force calculation by solving the gear transmission system dynamic model, gearbox vibration analysis by using finite element method (FEM), and boundary element analysis (BEA) of the sound field. In this method, a commercial software, LMS.Virtual.lab, is used to analyze the sound radiation for the gear reducer. The input data are fundamental performance parameters of the gear reducer, which consist of the gearbox shape, material, gear error, bearing stiffness, and so on. The output data are vibrations and noise analysis results, which consist of dynamic responses, frequency spectrum for noise, panel acoustic contribution, and so on. The low-noise gearbox is designed according to the conclusion of panel acoustic contribution and gearbox dynamic characteristics.

\section{Gearbox Excitation Calculation}

In a power transmission gear system, the gear pair assembly remains one of the major noise and vibration sources in
TABLE 1: The gear system parameters.

\begin{tabular}{lccccc}
\hline $\begin{array}{l}\text { Power } \\
(\mathrm{Kw})\end{array}$ & $\begin{array}{c}\text { Gear } \\
\text { ratio }\end{array}$ & $\begin{array}{c}\text { Module } \\
(\mathrm{mm})\end{array}$ & $\begin{array}{c}\text { Pressure } \\
\text { angle }(\mathrm{deg})\end{array}$ & $\begin{array}{c}\text { Face width } \\
(\mathrm{mm})\end{array}$ & $\begin{array}{c}\text { Rotational } \\
\text { speed }(\mathrm{r} / \mathrm{min})\end{array}$ \\
\hline 10 & $20 / 80$ & 3.0 & 20 & 60 & 1000 \\
\hline
\end{tabular}

the system. The vibrations of the gear transmission system are generated due to the fluctuation of the dynamic meshing force, which is affected by the time-varying mesh stiffness and errors.

3.1. Gear Time-Varying Mesh Stiffness. The gear system parameters are given in Table 1 . The variation of the mesh stiffness for the gear pair is obtained by using static finite element analysis, in which FEM Contact Algorithm is adopted.

The FE-model of the gear pair and boundary conditions is shown in Figure 2. During the calculation of the time-varying mesh stiffness, the driven gear is fixed, the torque $T$ is applied on the driving gear, and contact constraint is applied between the engaged tooth of the driving gear and the driven gear.

As a result of the tooth Hertzian contact deformations and tooth bending deformations, the driving gear will revolved a small angle $\theta$ on its centre. The small angle $\theta$ is obtained by solving the gear pair FE-model; then the total deformation of the meshing line is defined as

$$
u=\theta \cdot R_{b}
$$

where $R_{b}$ is the base radius of the driving gear.

So the mesh stiffness at this position is represented by the equation

$$
K=\frac{T}{\left(R_{b} u\right)}
$$

where $T$ is the torque.

Since the gear rotation is continuous, the gear meshing stiffness is periodic at the mesh frequency, a complete mesh cycle is divided into several steps, and the rotatory angle and position of the gears at every step can be calculated according to gear mesh theory. Then the calculation of the mesh stiffness is repeated at every gear engaging position. The time-varying mesh stiffness function is formed by cubic spline interpolation, as shown in Figure 3(a). As the number of tooth pairs in contact changes, abrupt changes in the gear pair stiffness occur (the mesh of spur gears with two tooth pairs in contact is roughly twice as stiff as when one tooth pair is in contact).

3.2. Gear Errors. Vibrations of gear pairs are largely affected by the amplitude and phase of deviations of the tooth profile from the true involute one, which is induced by gear manufacturing and installing errors. Meanwhile, with the effect of the gear errors on the instantaneous contact ratio, the collision and impact occur while the gear pair is running [12]. As a result, gear errors must be included in the gear transmission system model. Generally, the deviations are assumed to be small enough so that tooth contacts remain on 


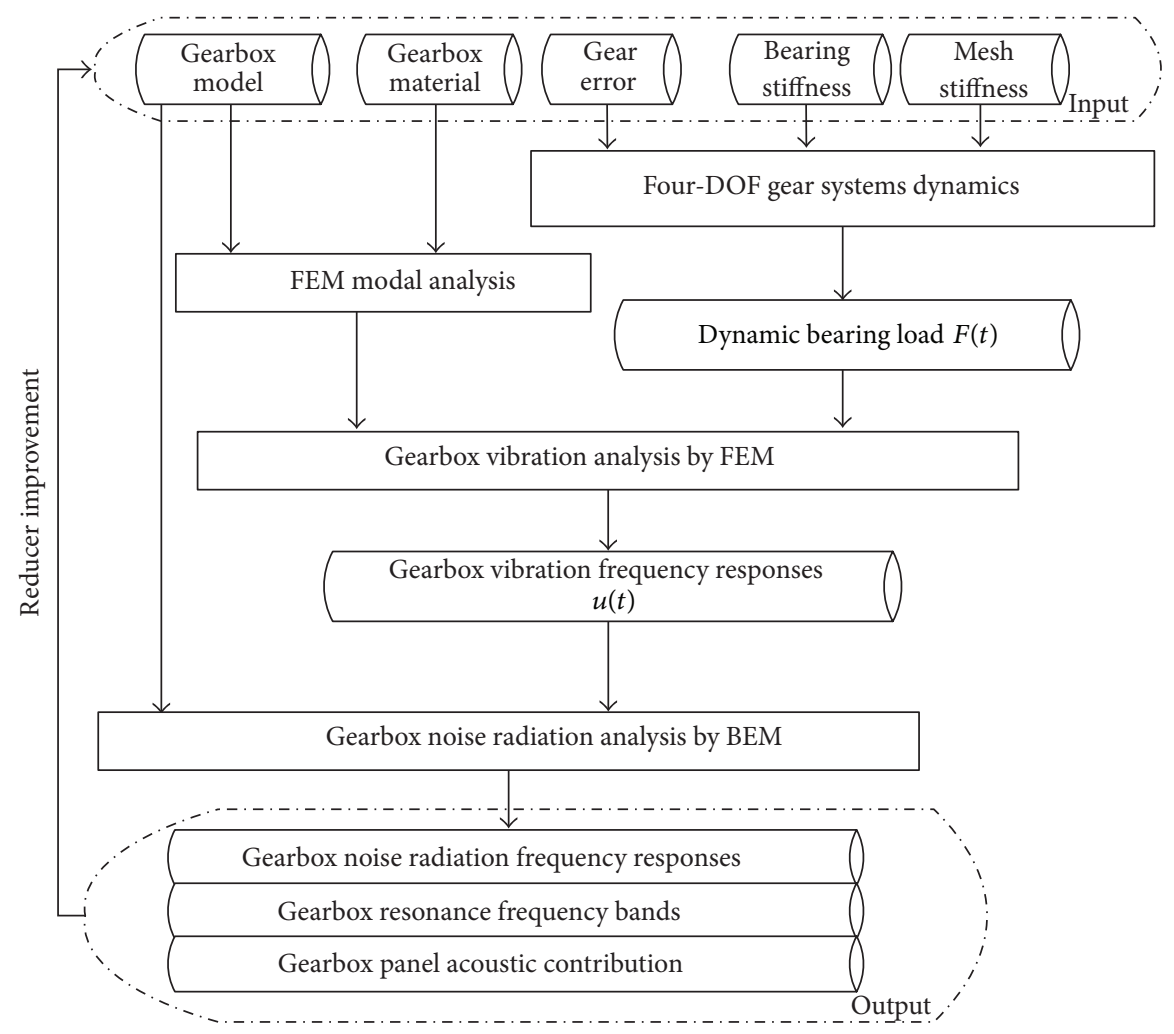

FIGURE 1: Analysis procedure of gear reducer noise radiation.

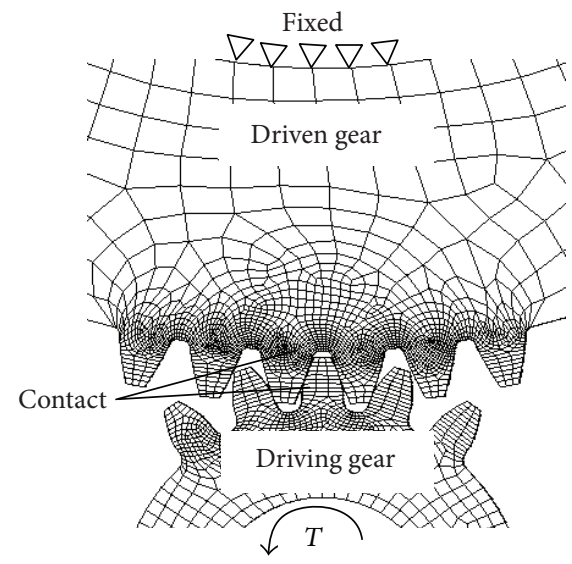

FIGURE 2: Gear pair finite element model.

the theoretical line of action [2]. Error function, representing the sum of pitch, profile, pressure angle, and run out errors, is supposed as displacement excitations along the tooth profile as a sine wave in the model. The harmonic function is used to simulate the gear error variation which is shown in Figure 3(b). The error function is written as

$$
e(t)=e_{r} \sin \left(\frac{w t}{T_{m}}+\phi\right)
$$

where $e_{r}$ is error amplitude, $T_{m}$ is the mesh cycle, $w$ is the angular velocity of the driving gear, and $\phi$ is the phase angle.
3.3. Gear Transmission Systems Dynamics Model. The proposed dynamic model of the gear pair is shown in Figure 4, which represents the driving gear (subscript $p$ ) meshing with driven gear (subscript $g$ ). The following assumptions are made in the model formulation.

(a) The deflection of the shaft is neglected, because the span of the bearings is little.

(b) Shaft mass and inertia are lumped at the gears.

(c) The bodies representing the two gear bodies are assumed to be rigid disks [13].

(d) The gear-shaft connections were assumed to be rigid, ignoring the stiffness of the connections and any consequent relative torsional motion between the shaft and gear hub.

(e) Gear pairs mesh flexibility and other parts flexibility are included in the form of a linear spring. The gear mesh stiffness is time variant; the support stiffness is constant.

Namely, $K_{p y}$ and $K_{g y}$ denote bearing stiffness of the driving gear and driven gear and $K_{m}$ denotes time-varying mesh stiffness. The angular displacements $\theta_{p}$ and $\theta_{g}$ of the driving gear and the driven gear are in the reversed direction; in the same time, the transverse displacements $Y_{p}$ and $Y_{g}$ in the direction of meshing line are considered.

The angular displacements and the transverse displacements of the gears will affect meshing state of the gear 


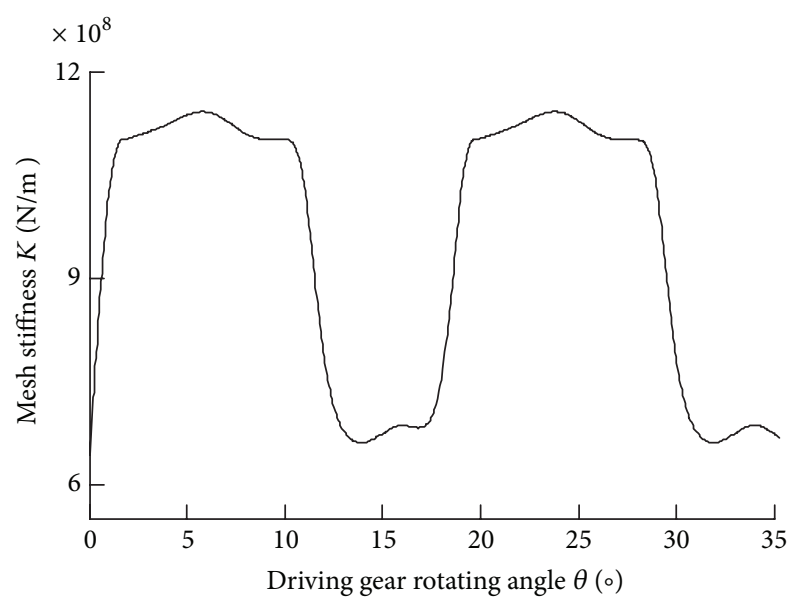

(a) Time-varying mesh stiffness

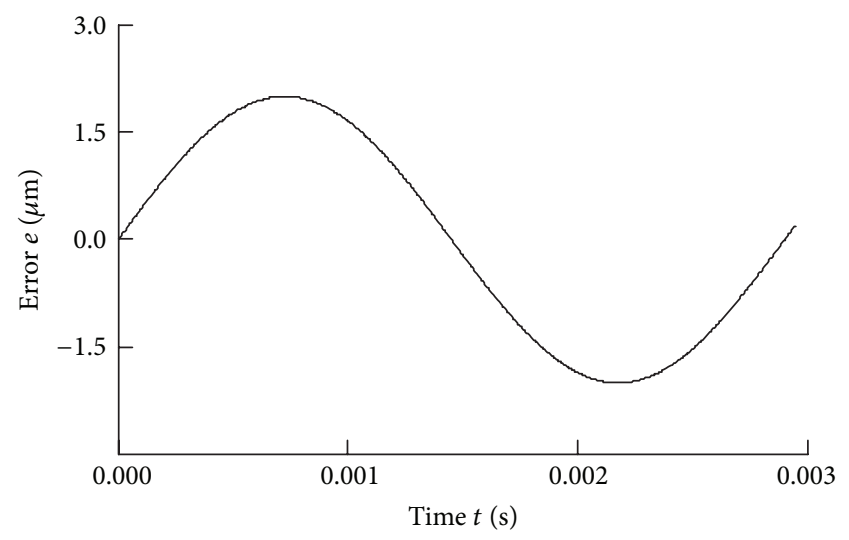

(b) Manufacture error

FIGURE 3: The transmission system excitation.

pair, so the displacement is transformed to action line. The displacement on the action line is written as

$$
\bar{y}_{p}=R_{p} \theta_{p}-y_{p}, \quad \bar{y}_{g}=y_{g}-R_{g} \theta_{g}
$$

where $R_{p}$ is the base circle radius of the driving gear and $R_{g}$ is the base circle radius of the driven gear.

The mesh force and damping force of the gear pairs are written as

$$
\begin{gathered}
F_{k}=k_{m}\left(\bar{y}_{p}+\bar{y}_{g}-e\right)=k_{m}\left(R_{p} \theta_{p}-y_{p}+y_{g}-R_{g} \theta_{g}-e\right), \\
F_{c}=c_{m}\left(\dot{\bar{y}}_{p}+\dot{\bar{y}}_{g}-e\right)=c_{m}\left(R_{p} \dot{\theta}_{p}-\dot{y}_{p}+\dot{y}_{g}-R_{g} \dot{\theta}_{g}-\dot{e}\right),
\end{gathered}
$$

where $e$ is the gear error, $R_{p}$ is the base circle radius of the driving gear, $R_{g}$ is the base circle radius of the driven gear, and $c_{m}$ is mesh damping coefficient of gear pair $c_{m}=$ $2 \xi \sqrt{k_{m} /\left(1 / m_{p}+1 / m_{g}\right)}, m_{p}$ is the mass of the driving gear and $m_{g}$ is mass driven gear of the driven gear. The range of the damping ratio $\xi$ is $0.03 \sim 0.1$.

Therefore, dynamic mesh force $F_{p g}$ is defined as

$$
F_{p g}=F_{k}+F_{c}
$$

Similarly, supporting spring force (bearing force) is defined as

$$
F_{p y}=k_{p y} y_{p}, \quad F_{g y}=k_{g y} y_{g}
$$

According to the Newton mechanics law, the following differential equations of the gear system are set up, which contains

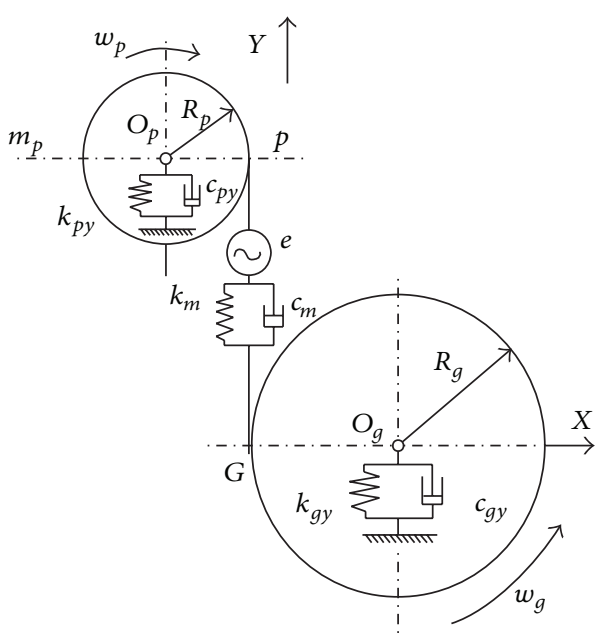

Figure 4: The dynamic model of the system.

the effects of time-varying mesh stiffness and error excitation. Total number of degree of freedom for the model is 4 :

$$
\begin{gathered}
m_{p} \ddot{y}_{p}+c_{p y} \dot{y}_{p}+k_{p y} y_{p}=F_{p g}, \\
I_{p} \ddot{\theta}_{p}=T_{p}-F_{p g} R_{p}, \\
m_{g} \ddot{y}_{g}+c_{g y} \dot{y}_{g}+k_{g y} y_{g}=-F_{p g}, \\
I_{g} \ddot{\theta}_{g}=T_{g}-F_{p g} R_{g} .
\end{gathered}
$$

Here, $T_{p}$ is the input torque. $T_{g}$ is the load torque. $I_{p}$ is the rotational inertia of driving gear. $I_{g}$ is the rotational inertia of driven gear. 
Equation (6) in conjunction with (8) yields 4 coupled homogeneous ordinary differential equations in the form

$$
\begin{gathered}
m_{p} \ddot{y}_{p}+c_{p y} \dot{y}_{p}+k_{p y} y_{p} \\
=c_{m}\left(R_{p} \dot{\theta}_{p}-\dot{y}_{p}+\dot{y}_{g}-R_{g} \dot{\theta}_{g}-\dot{e}\right) \\
+k_{m}\left(R_{p} \theta_{p}-y_{p}+y_{g}-R_{g} \theta_{g}-e\right), \\
I_{p} \ddot{\theta}_{p}=-\left[c_{m}\left(R_{p} \dot{\theta}_{p}-\dot{y}_{p}+\dot{y}_{g}-R_{g} \dot{\theta}_{g}-\dot{e}\right)\right. \\
\left.\quad+k_{m}\left(R_{p} \theta_{p}-y_{p}+y_{g}-R_{g} \theta_{g}-e\right)\right] R_{p}+T_{p}, \\
m_{g} \ddot{y}_{g}+c_{g y} \dot{y}_{g}+k_{g y} y_{g} \\
=-c_{m}\left(R_{p} \dot{\theta}_{p}-\dot{y}_{p}+\dot{y}_{g}-R_{g} \dot{\theta}_{g}-\dot{e}\right) \\
\quad-k_{m}\left(R_{p} \theta_{p}-y_{p}+y_{g}-R_{g} \theta_{g}-e\right), \\
I_{g} \ddot{\theta}_{g}=\left[c_{m}\left(R_{p} \dot{\theta}_{p}-\dot{y}_{p}+\dot{y}_{g}-R_{g} \dot{\theta}_{g}-\dot{e}\right)\right. \\
\left.+k_{m}\left(R_{p} \theta_{p}-y_{p}+y_{g}-R_{g} \theta_{g}-e\right)\right] R_{g}+T_{g} .
\end{gathered}
$$

In the mathematical model, the angular displacements $\theta_{p}$ and $\theta_{g}$ are independent variables. In order to solve the equations, the angular displacements should be transformed into an independent variable. Therefore, transmission error is lead into the model, defined $y_{p g}=R_{p} \theta_{p}-R_{g} \theta_{g}$; then rigid body displacement is removed; the model can be written as

$$
\begin{aligned}
& m_{p} \ddot{y}_{p}+c_{p y} \dot{y}_{p}-c_{m}\left(\dot{y}_{p g}-\dot{y}_{p}+\dot{y}_{g}\right)+k_{p y} y_{p} \\
& \quad-k_{m}\left(y_{p g}-y_{p}+y_{g}\right)=-c_{m} \dot{e}-k_{m} e, \\
& m_{g} \ddot{y}_{g}+c_{g y} \dot{y}_{g}+c_{m}\left(\dot{y}_{p g}-\dot{y}_{p}+\dot{y}_{g}\right)+k_{g y} y_{g} \\
& \quad+k_{m}\left(y_{p g}-y_{p}+y_{g}\right)=c_{m} \dot{e}+k_{m} e, \\
& m_{g p} \ddot{y}_{p g}+c_{m}\left(\dot{y}_{p g}-\dot{y}_{p}+\dot{y}_{g}\right)+k_{m}\left(y_{p g}-y_{p}+y_{g}\right) \\
& =c_{m} \dot{e}+k_{m} e-\frac{F_{g} m_{p g}}{\bar{m}_{g}}+\frac{F_{p} m_{p g}}{\bar{m}_{p}},
\end{aligned}
$$

where $m_{p g}$ is equivalent mass of the gear pair, $m_{p g}=\bar{m}_{p} \bar{m}_{g} /$ $\left(\bar{m}_{p}+\bar{m}_{g}\right), \bar{m}_{p}=I_{p} / R_{p}^{2}, \bar{m}_{g}=I_{g} / R_{g}^{2}, F_{p}=T_{p} / R_{p}$, and $F_{g}=$ $T_{g} / R_{g}$.

The equation of motion is given in the matrix form as

$$
[M]\{\ddot{X}\}+[C]\{\dot{X}\}+K(t)\{X\}=\{P(t)\}
$$

where $M$ is the mass matrix, $C$ is the damping matrix, $K(t)$ is the stiffness matrix, $X$ is the vector of the displacement, and $P(t)$ is the vector of the load. The mass matrix, the damping matrix, the stiffness matrix, and load vector are given, respectively, as

$$
\begin{aligned}
& {[M]=\left[\begin{array}{ccc}
m_{p} & & 0 \\
0 & m_{g} & m_{p g}
\end{array}\right],} \\
& {[C]=\left[\begin{array}{ccc}
c_{p y}+c_{m} & -c_{m} & -c_{m} \\
-c_{m} & c_{g y}+c_{m} & c_{m} \\
c_{m} & -c_{m} & -c_{m}
\end{array}\right] \text {, }} \\
& {[K]=\left[\begin{array}{ccc}
k_{p y}+k_{m} & -k_{m} & -k_{m} \\
-k_{m} & k_{g y}+k_{m} & k_{m} \\
k_{m} & -k_{m} & -k_{m}
\end{array}\right] \text {, }} \\
& \{P\}=\left\{\begin{array}{c}
-c_{m} \dot{e}-k_{m} e \\
c_{m} \dot{e}+k_{m} e \\
-c_{m} \dot{e}-k_{m} e+\frac{F_{g} m_{p g}}{\bar{m}_{g}}-\frac{F_{p} m_{p g}}{\bar{m}_{p}}
\end{array}\right\} \text {. }
\end{aligned}
$$

3.4. Dynamic Bearing Force. Equation (11) is solved by using the Newmark time integration method. The Newmark method is a generalization of the linear acceleration method [14]. This latter method assumes that the acceleration varies linearly within the interval $(t+\Delta t)$. This give

$$
\begin{gathered}
\left\{\ddot{x}_{n}\right\}=\left\{\ddot{x}_{t}\right\}+\frac{1}{\Delta t}\left(\left\{\ddot{x}_{t+\Delta t}\right\}-\left\{\ddot{x}_{t}\right\}\right), \\
\left\{\dot{x}_{t+\Delta t}\right\}=\left\{\dot{x}_{t}\right\}+\left[(1-\delta)\left\{\dot{x}_{t}\right\}+\delta\left\{x_{t+\Delta t}\right\}\right] \Delta t \\
\left\{x_{t+\Delta t}\right\}=\left\{x_{t}\right\}+\left\{\dot{x}_{t}\right\} \Delta t+\left[\left(\frac{1}{2}-\beta\right)\left\{\ddot{x}_{t}\right\}+\beta\left\{x_{t+\Delta t}\right\}\right] \Delta t^{2} .
\end{gathered}
$$

The response at time $t+\Delta t$ is obtained by evaluating the equation of motion at time $t+\Delta t$. The Newmark method is, therefore, an implicit method.

The Newmark method is unconditionally stable provided

$$
\delta \geq 0.5, \quad \beta \geq \frac{1}{4}(\delta+0.5)^{2} .
$$

One can find that $\delta \geq 0.5$ and $\beta=0.5$ lead to acceptable results for most of problems, $\delta \geq 0.5$ and $\beta=0.5$ are always used in this paper for simplification.

The dynamic bearing force is shown in Figure 5. Dynamic bearing force presents periodic fluctuations and the major components at 4 times, 5 times, and 6 times the mesh frequency $(333 \mathrm{~Hz})$.

\section{Analysis of Gearbox Vibration and Noise Radiaton}

4.1. Gearbox FE-Model. The gear reducer model is shown in Figure 6. In order to predict the noise of the transmission system during operation, vibration of the gearbox must 


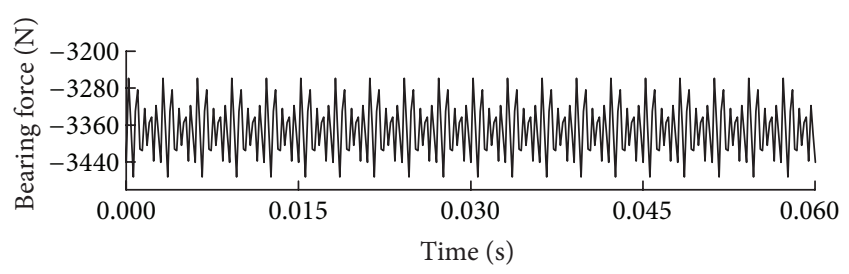

(a) The time history of dynamic pinion bearing force

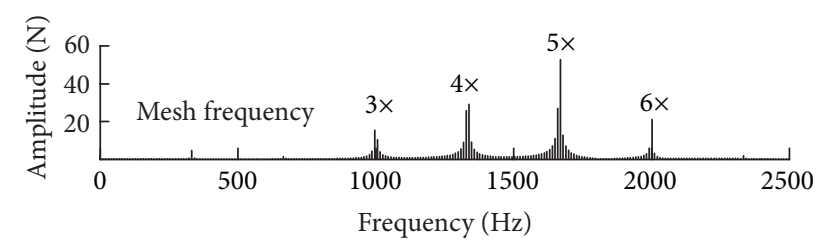

(b) Frequency spectra of dynamic pinion bearing force

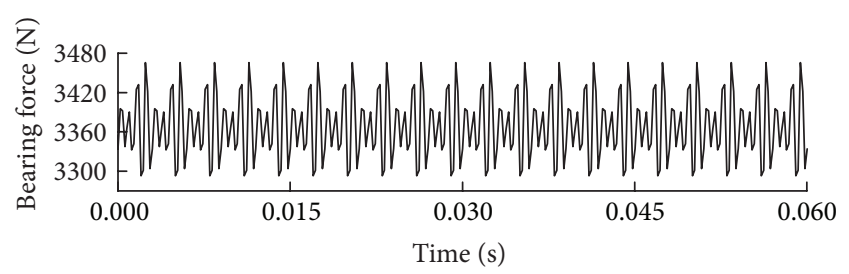

(c) The time history of dynamic wheel bearing force

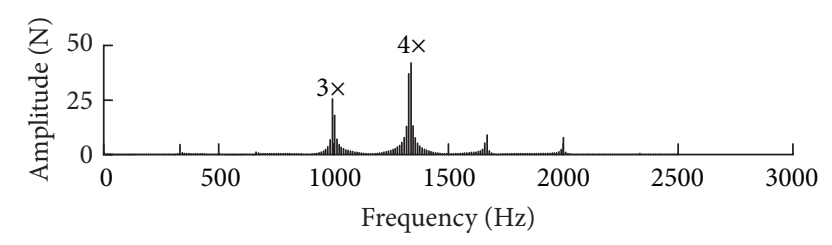

(d) Frequency spectra of dynamic wheel bearing force

FIGURE 5: The dynamic bearing force.

be accurately computed. The finite element model of the realistic character gearbox is built up by using the commercial software ANSYS and shown in Figure 7. The model consisted of 146238 elements and 38634 nodes. The material of the gearbox is cast steel, whose elastic modulus $E=207 \mathrm{GPa}$, Poisson ratio $v=0.3$, and density $\rho=7800 \mathrm{Kg} / \mathrm{m}^{3}$. The bolt holes in the bottom of the gearbox are fixed, due to the gearbox connected with the base through the holes. For the convenience of dynamic load applying, a node is created in the center of the bearing bore; then the center node is coupled with the node on the inside surface of the bearing bore and the dynamic load is applied.

4.2. Gearbox Vibration Modal Analysis. The Lanczos method is used in the modal analysis of the gearbox. Eight modes in the frequency range 0 to $3000 \mathrm{~Hz}$, shown in Figure 8, are chosen to represent the vibration of the gearbox. The vibration of the bottom half gearbox is not as intense as the upper half, because there are bolt constraints and the support of the stiffeners on the bottom of the gearbox.

4.3. Studies of Gearbox Dynamic Response. During the process of dynamic response solution, the dynamic load which

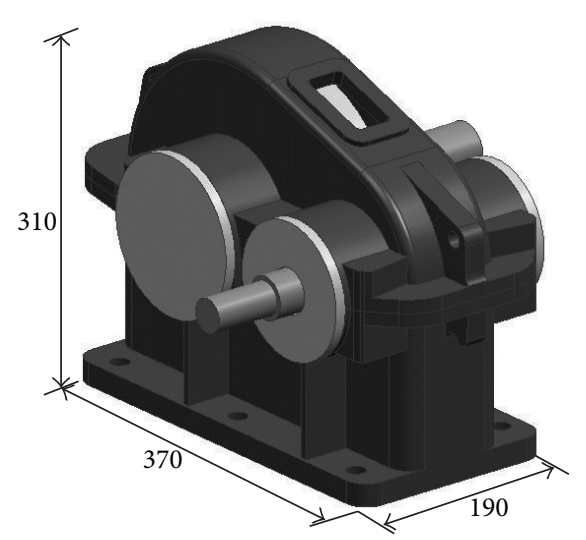

Figure 6: The gear box three-dimensional model.

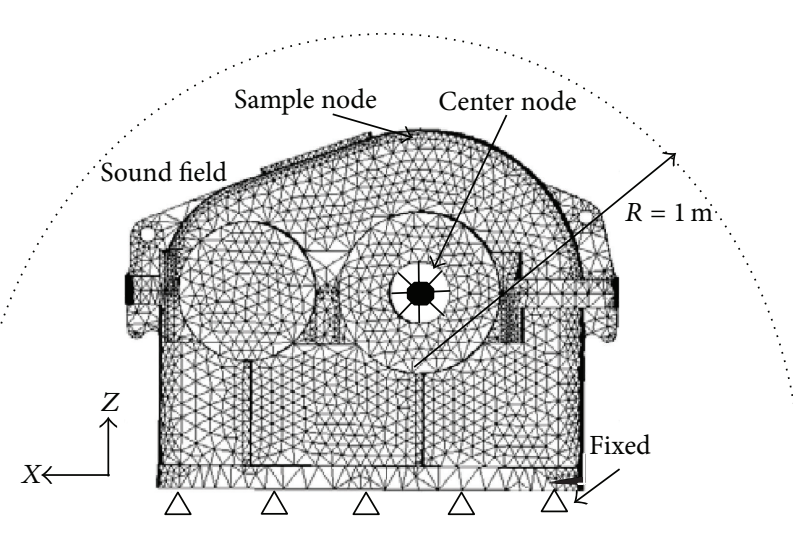

FIgURE 7: The gear box FE-model.

is acted on the bearing should be transformed into discrete impact load; then structure response is computed under the impact load step by step, until it achieves steady state.

For the modal superposition method is used in the dynamic response calculation; all the modes which are influential to dynamic response should be calculated; otherwise the result will not be accurate due to the absence of modes. Nearly 200 vibrational modes are used in the calculation; the maximum natural frequency is $20000 \mathrm{~Hz}$.

Figure 9 is the time domain dynamic response signal and corresponding frequency spectra of the signal for the node on the gearbox top surface. Figure 9(a) shows the node dynamic response (displacement) at operating speed of $1000 \mathrm{rpm}$. Note that the largest amplitude of the response is $1.6 \mu \mathrm{m}$.

Figure 9(b) shows the frequency components of the response. The major vibration components occur at 3 times, 4 times, and 5 times the mesh frequency $(333 \mathrm{~Hz})$. The very large amplitude in the frequency components at the range of $1550 \mathrm{~Hz} \sim 1700 \mathrm{~Hz}$ is due to the fact that the gearbox forth natural frequency is near the 5 times $(1650 \mathrm{~Hz})$ the mesh frequency, and the mode shape is twisting of the upper half of the gearbox. The fundamental and the 2 times mesh frequency component are substantially smaller due to the lack of any gearbox natural frequencies near $333 \mathrm{~Hz}$ and $666 \mathrm{~Hz}$. 


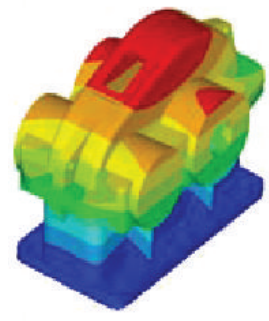

Mode 1: frequency, $675.8 \mathrm{~Hz}$

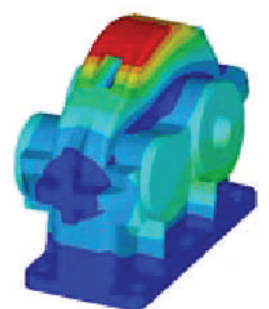

Mode 5: frequency, $2375.3 \mathrm{~Hz}$

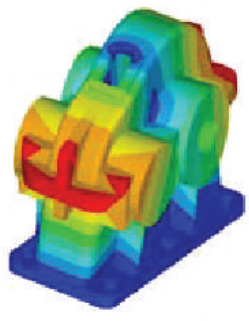

Mode 2: frequency, $1339.8 \mathrm{~Hz}$

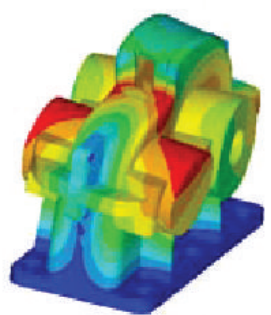

Mode 6: frequency, $2729.2 \mathrm{~Hz}$

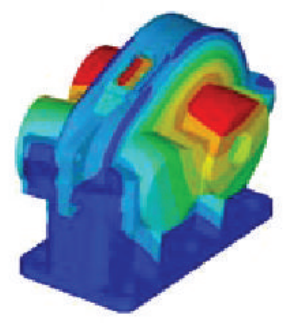

Mode 3: frequency, $1519.7 \mathrm{~Hz}$

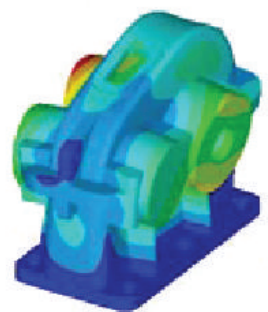

Mode 7: frequency, $2783.3 \mathrm{~Hz}$

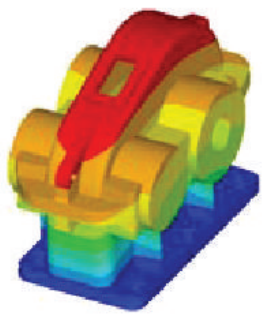

Mode 4: frequency, $1662 \mathrm{~Hz}$

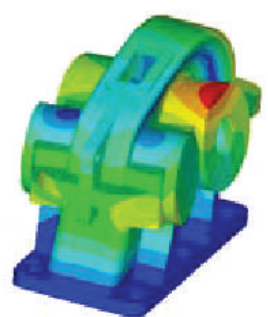

Mode 8: frequency, $2885.3 \mathrm{~Hz}$

FIGURE 8: The mode shapes of the gearbox.

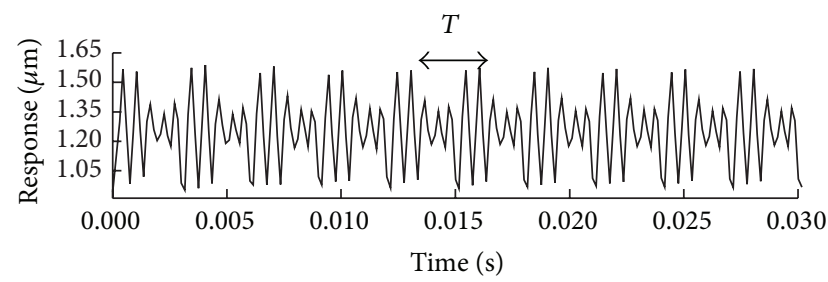

(a) Node-displacement response

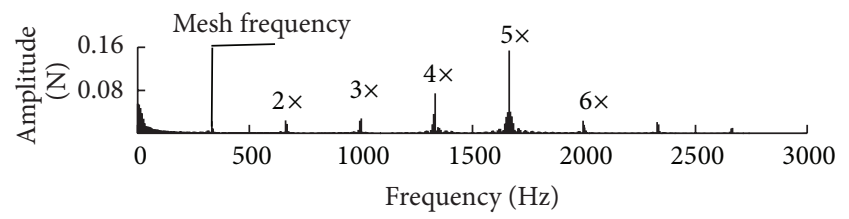

(b) Vibration frequency spectra

Figure 9: The gear box dynamic response.

4.4. Gearbox Frequency Spectrum for Noise. The frequency responses corresponding to the calculated vibration velocities of the surface of the gearbox are inputted into the BEM to analyze the distribution of sound-pressure levels around the gearbox. In order to ensure that the vibration data transmission is correct, both the BE-model and FE-model are meshed in the same way, where the nodes of the two models are mutually corresponding.

Hemispherical sound field is defined outside of the gearbox and is shown in Figure 6. Three representative field points are selected in the sound field; they are located at the top of the gearbox (field point a) and the left and right sides of the gearbox (field points $b$ and $c$ ). The frequency

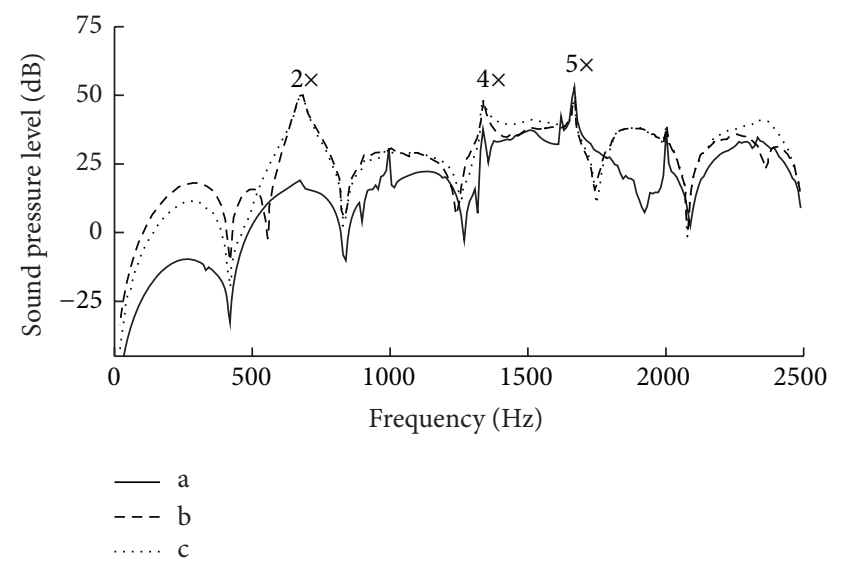

FIgURE 10: The frequency spectrum for noise.

response of sound pressure level is shown in Figure 10. The noise of the field point at top gearbox is lower than right and left side, due to the fact that most of the mode shapes are swing or torsional vibrations that make normal vibration of the gearbox side plate more violent than top surface. The amplitudes and general shapes of the curves $b$ and $\mathrm{c}$ are similar; the frequency components of considerable magnitudes are observed at the mesh frequency of $333 \mathrm{~Hz}$ and doubling frequency with three very large components at the 2 times mesh frequency, 4 times mesh frequency, and 5 times mesh frequency; the largest peak value is $50 \mathrm{~dB}$. When the frequency of excitation is larger than $1665 \mathrm{~Hz}$, the sound pressure level is decreased as the frequency increases. 


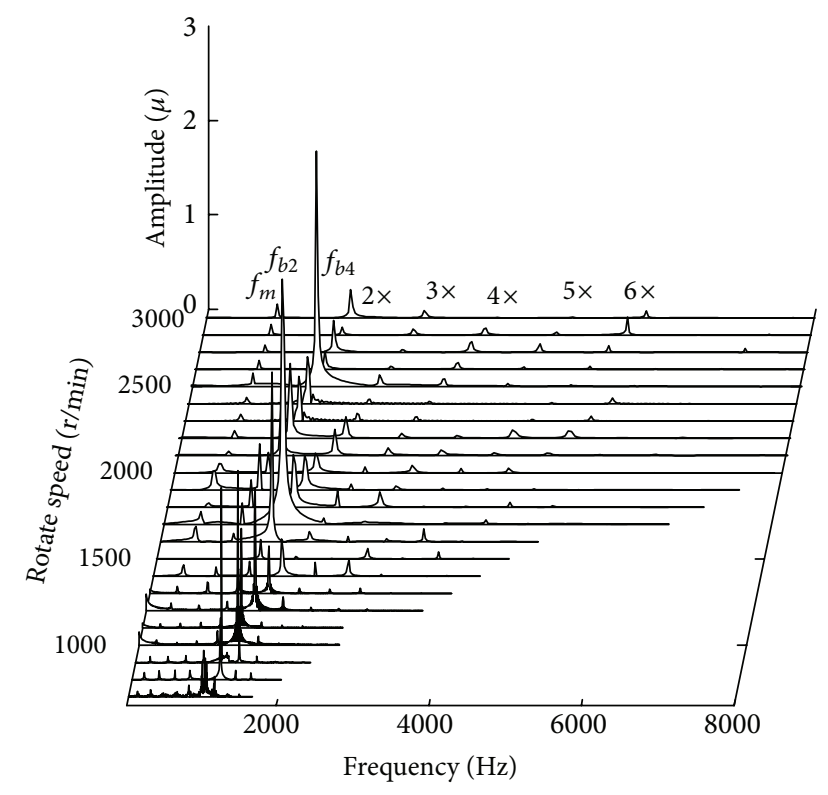

FIGURE 11: The waterfall of the gearbox dynamic response.

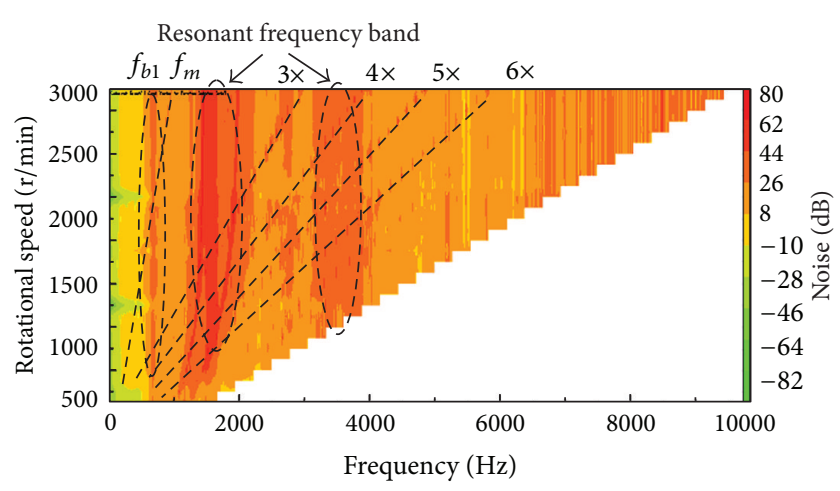

FIGURE 12: The waterfall of the gearbox noise.

\section{The Effect of Rotation Speed on the Vibration and Noise}

With change of the rotational speed, not only the gear pair meshing state will change, but also the frequency of the various harmonics will change at the same time. In order to research the effect of the rotation speed, the dynamic bearing force, gearbox vibration, and noise radiation are calculated when the rotation speed is within the range of $500 \mathrm{r} / \mathrm{min}$ and $3000 \mathrm{r} / \mathrm{min}$.

5.1. The Effect of Rotation Speed on the Gearbox Dynamic Response. Increasing the input speed steadily from $500 \mathrm{r} / \mathrm{min}$ to $3000 \mathrm{r} / \mathrm{min}$, a family of vibration and noise spectrum is obtained. Thus, two waterfall diagrams have been created, as shown in Figure $11\left(f_{g}\right.$ denotes mesh frequency; $f_{b 2}$ and $f_{b 4}$ denote the second and forth nature frequency of the gearbox).

The spectral map illustrates how the various harmonics fall along radial lines and can, thus, be separated from

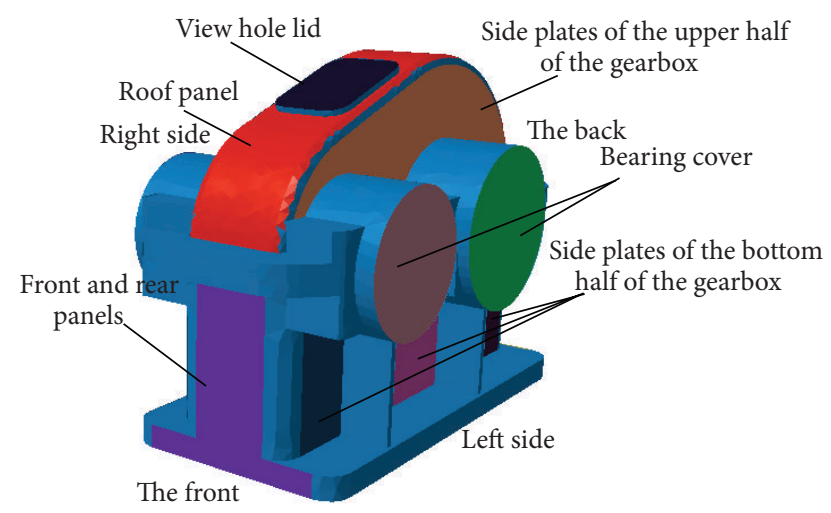

FIGURE 13: The gear box panel definition. View hole lid (1); roof panel $(2)$; side plates of the upper half of the gearbox $(3,4)$; bearing cover $(5,6,7$, and 8$)$; side plates of the bottom half of the gearbox $(9,10,11$, 12,13 , and 14); front and rear panels $(15,16)$.

the constant frequency components due to excessive amplification by a structural resonance. The excitation consists of harmonic components whose frequency is a multiple of the corresponding gear's rotational speed, so the major components of response fall along radial lines. Meanwhile, the gearbox produces violent vibration near $1664 \mathrm{~Hz}$ in different rotational speed, since the 2 times the mesh frequency in $2500 \mathrm{r} / \mathrm{min}, 3$ times the mesh frequency in $1600 \mathrm{r} / \mathrm{min}, 4$ times the mesh frequency in $1250 \mathrm{r} / \mathrm{min}$, and 5 times the mesh frequency in $1000 \mathrm{r} / \mathrm{min}$ are equal to the fourth natural frequency; the same phenomenon occurs near the second and third natural frequency. So it means that the second, third, and fourth natural frequency are sensitive to the dynamic bearing force.

5.2. The Effect of Rotation Speed on the Gearbox Noise Radiation. The gearbox noise spectral map in $\mathrm{dB}$ is shown in Figure 12. Note that the frequency components of the gearbox noise spectrum are not intense at low speed, as the rotational speed increases, and noise radiation was gradually strengthened. The distribution of sound pressure and dynamic response are consistent under various speeds; the resonant frequency band is produced at the range of $670 \mathrm{~Hz}, 1300-1700 \mathrm{~Hz}$, and $3000-4000 \mathrm{~Hz}$, which are near the gearbox natural frequency. So in order to reduce the gearbox vibration and noise radiation, the vibration at the resonant frequency band should be reduced during the gearbox design stage.

\section{Gearbox Improvement}

6.1. Gearbox Panel Acoustic Contribution. The vibration and noise of the gearbox are sensitive to the shape and structure of its housing. It is necessary to determine the noise contribution of each panel in the resonance region, which provide forceful basis as the gearbox structure is improved.

In order to quantify the noise proportion of each plate to the whole structure, we introduce the concept of panel acoustic contribution coefficient, which is the ratio of the noise 


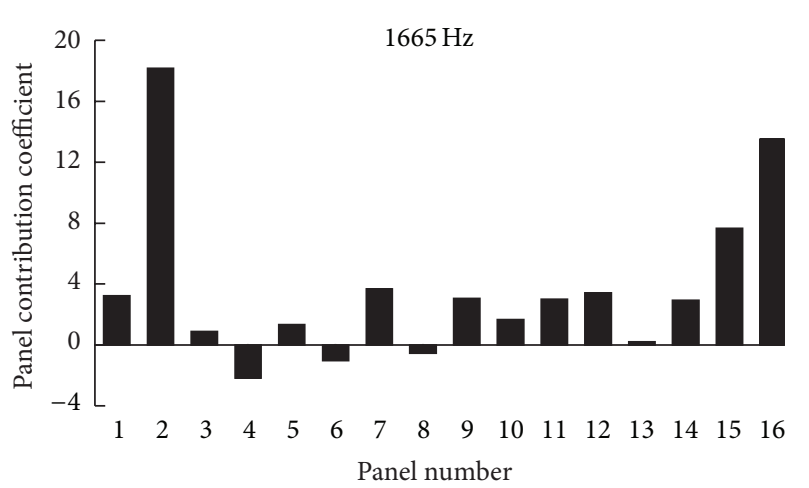

(a) Panel contribution at $1665 \mathrm{~Hz}$

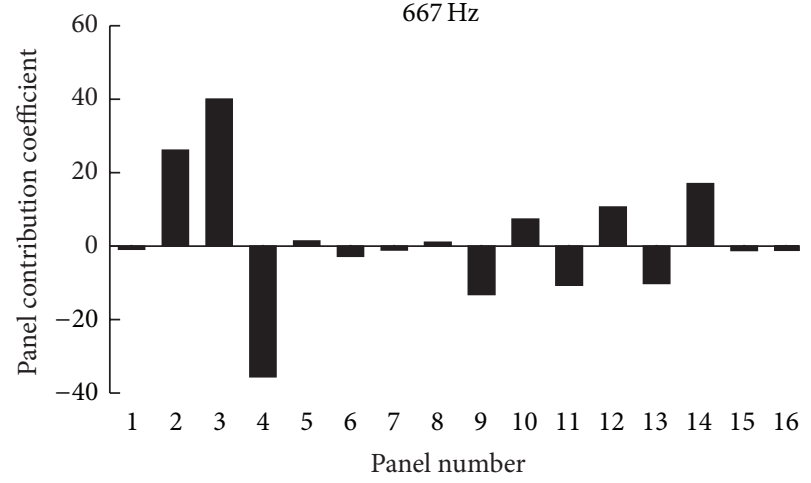

(b) Panel contribution at $667 \mathrm{~Hz}$

FIgURE 14: The gear box panel contribution.
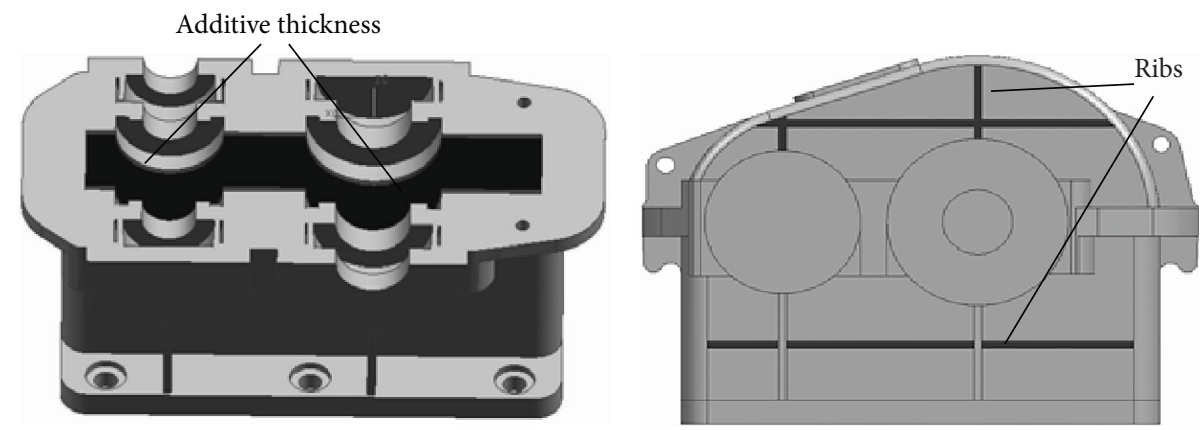

FIGURE 15: Improved gearbox.

pressure produced by vibration of the panels to the overall noise pressure:

$$
D_{e}=R_{e} \frac{P_{e} P^{*}}{|P|^{2}},
$$

where $P^{*}$ is the conjugate complex number of the sound pressure for the point and $R$ is its real part.

If the phase difference between the panel sound pressure and the overall sound pressure is less than $90^{\circ}$, the overall sound pressure will increase with the raise of the panel vibration velocity, and the contribution coefficient is defined as positive; otherwise, it is negative. The radiating noise can be reduced effectively if vibration of the panels whose acoustic contributions are positive and values are large can be reduced.

Each closed surface of the gearbox is defined as a panel, and the part whose radiation area is too small is neglected, such as the area of corner cutting. The whole gearbox outer surface is divided into 16 panels, as shown in Figure 13.

The panel acoustic contribution coefficient is shown in Figure 14, noted that the contributions of the roof panel and the front and rear panels are greater than other panels when the excitation frequency is $1665 \mathrm{~Hz}$. When the excitation frequency is $667 \mathrm{~Hz}$, the contributions of the roof and side plates of the upper half of the gearbox are bigger. Further analysis indicates that the noise is mainly caused by the panels of the upper half of the gearbox. Reducing vibrant intensity of
TABLE 2: The gear box natural frequencies $(\mathrm{Hz})$.

\begin{tabular}{lccc}
\hline Mode steps & Original model & Plan 1 & Plan 2 \\
\hline 1st & 716.5 & 791.2 & 770.7 \\
2nd & 1518.8 & 1684.4 & 1631.8 \\
3rd & 1682.3 & 1847.2 & 1800.1 \\
4th & 1843.7 & 2138.1 & 2001.4 \\
5th & 2459 & 2887 & 2765.3 \\
6th & 2881.6 & 3178.4 & 3010.8 \\
7th & 2887.3 & 3431.6 & 3259.4 \\
8th & 3043.9 & 3434.3 & 3276.9 \\
\hline
\end{tabular}

the panels $2,3,4,15$, and 16 is important to noise control of the gear reducer.

6.2. Gearbox Improvement. In order to reduce the intensity of vibration of the upper half of the gearbox and make the gearbox natural frequency avoid the 2 times and 5 times the mesh frequency, two low-noise design plans are proposed. The first plan increases the thickness of the side plates of the bottom half of the gearbox with $4 \mathrm{~mm}$. Another one, the gearbox stiffness was strengthened by using ribs on the side plates, as Figure 15 shown. The natural frequency is shown in Table 2. 


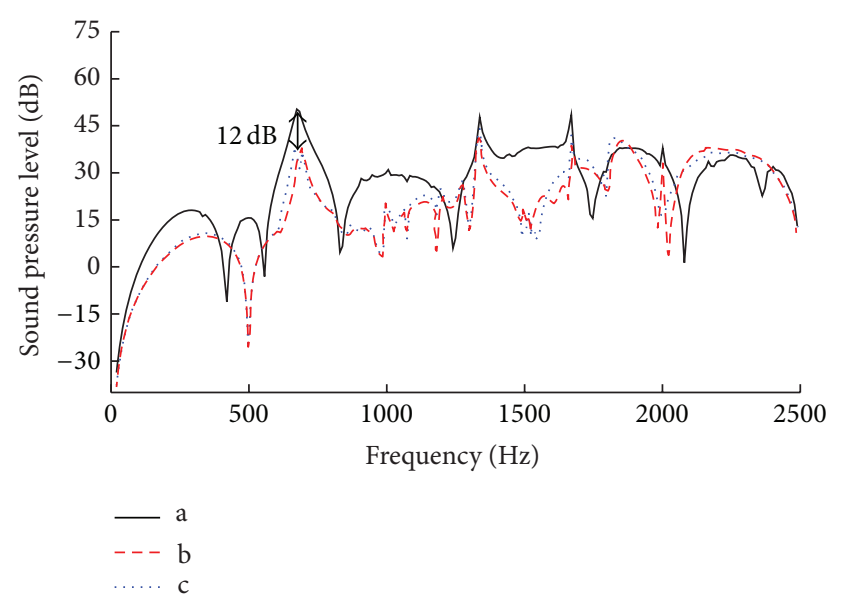

FIGURE 16: The frequency spectrum for noise.

The frequency-noise spectra of the gearbox pre- and postimprovement are shown in Figure 16, where curves a, b, and $c$ represent the distribution of sound pressure level for the original model and the improved models, respectively. As can be seen, the differences in mesh frequency doubling are considerable. The noise of improved gearbox is reduced obviously when the extinction frequency is below $1700 \mathrm{~Hz}$. The sound pressure level is reduced about $12 \mathrm{~dB}$ at $665 \mathrm{~Hz}$ and about $9 \mathrm{~dB}$ at $1332 \mathrm{~Hz}$ in magnitude.

With comparative analysis of the two low-noise design plans, the effect of increasing gearbox thickness and ribs on reducing noise and vibration is almost the same, but plan 1 will increase more weight and take up more interior room, so it is more realizable to provide stiffening ribs on the gearbox.

\section{Conclusions and Summary}

A procedure for predicting the vibration and noise of gear reducer is developed, in which both gear transmission system dynamic characteristics and gearbox dynamic characteristics are considered. The dynamic bearing force is taken as the excitation; the gearbox vibrations and noise radiating are calculated by using FEM/BEM. The resonant frequency band of the gearbox is obtained. Then the low-noise gearbox was designed based on the result of modal analysis and acoustic panel contribution analysis. It is available to reduce the noise radiation of the gearbox through increasing the structural stiffness of the gearbox and reducing the vibration of the panels whose acoustic contribution coefficients are positive and values are large.

\section{Conflict of Interests}

The authors declare that there is no conflict of interests regarding the publication of this article.

\section{References}

[1] M. S. Abbes, S. Bouaziz, F. Chaari, M. Maatar, and M. Haddar, "An acoustic-structural interaction modelling for the evaluation of a gearbox-radiated noise," International Journal of Mechanical Sciences, vol. 50, no. 3, pp. 569-577, 2008.

[2] P. Velex and M. Maatar, "A mathematical model for analyzing the influence of shape deviations and mounting errors on gear dynamic behaviour," Journal of Sound and Vibration, vol. 191, no. 5, pp. 629-660, 1996.

[3] J.-L. Dion, S. Le Moyne, G. Chevallier, and H. Sebbah, "Gear impacts and idle gear noise: experimental study and non-linear dynamic model," Mechanical Systems and Signal Processing, vol. 23, no. 8, pp. 2608-2628, 2009.

[4] M. Barthod, B. Hayne, J.-L. Tébec, and J.-C. Pin, "Experimental study of dynamic and noise produced by a gearing excited by a multi-harmonic excitation," Applied Acoustics, vol. 68, no. 9, pp. 982-1002, 2007.

[5] M. Kato, K. Inoue, K. Shibata, and H. Zhou, "Evaluation of sound power radiated by a gearbox," in Proceedings of the International Gearing Conference (Inter Gearing '94), pp. 69-74, Newcastle, UK, 1994.

[6] F. B. Oswald, D. P. Townsend, M. J. Valco, R. H. Spencer, R. J. Drago, and L. W. Joseph, "Influence of gear design parameters on gearbox radiated noise," in Proceedings of the International Gearing Conference (Inter Gearing '94), Newcastle, UK, September 1994.

[7] F. K. Choy, W. Qian, J. J. Zakrajsek, and F. B. Oswald, "Vibration and noise analysis of a gear transmission system," in Proceedings of the 29th Jiont Propulsion Conference and Exhibit, Monterey, Calif, USA, June 1993.

[8] Z. Yanyan and G. Zhen, "Analysis and Control of Gearbox Noise," China Mechanical Engineering, vol. 2, no. 5, pp. 55-57, 1994.

[9] A. Kahraman and G. W. Blankenship, "Effect of involute contact ratio on spur gear dynamics," Journal of Mechanical Design, vol. 121, no. 1, pp. 112-118, 1999.

[10] S. C. Kostić and M. Ognjanović, "The noise structure of gear transmission units and the role of gearbox walls," FME Transactions, vol. 35, no. 2, pp. 105-112, 2007.

[11] J. Tuma, "Gearbox noise and vibration prediction and control," International Journal of Acoustics and Vibrations, vol. 14, no. 2, pp. 99-108, 2009.

[12] T.-J. Lin, R.-K. Jiang, R.-F. Li, and W. Liu, "Numerical simulation of dynamic response and shock resistance of marine gearbox," Journal of Vibration and Shock, vol. 26, no. 12, pp. 1422, 2007.

[13] L. Runfang and W. Jianjun, System of the Gear Vibration Theory, Science Press, Beijing, China, 1997.

[14] Y. T. Gu and G. R. Liu, "A meshless local petrov-galerkin (MLPG) method for free and forced vibration analyses for solids," Computational Mechanics, vol. 27, no. 3, pp. 188-198, 2001. 


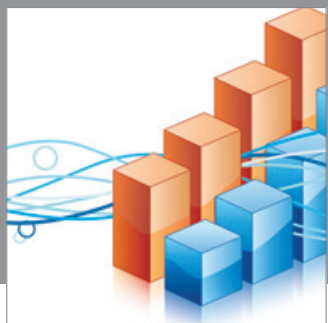

Advances in

Operations Research

mansans

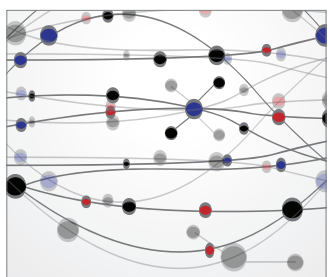

The Scientific World Journal
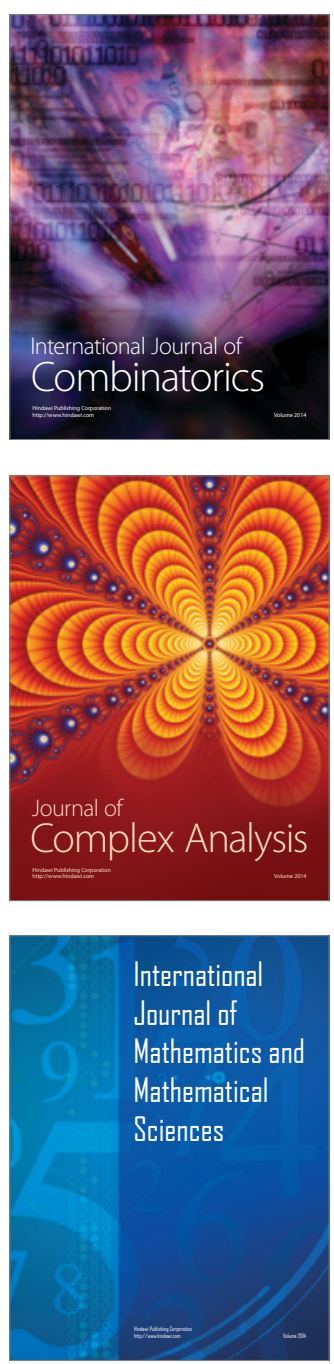
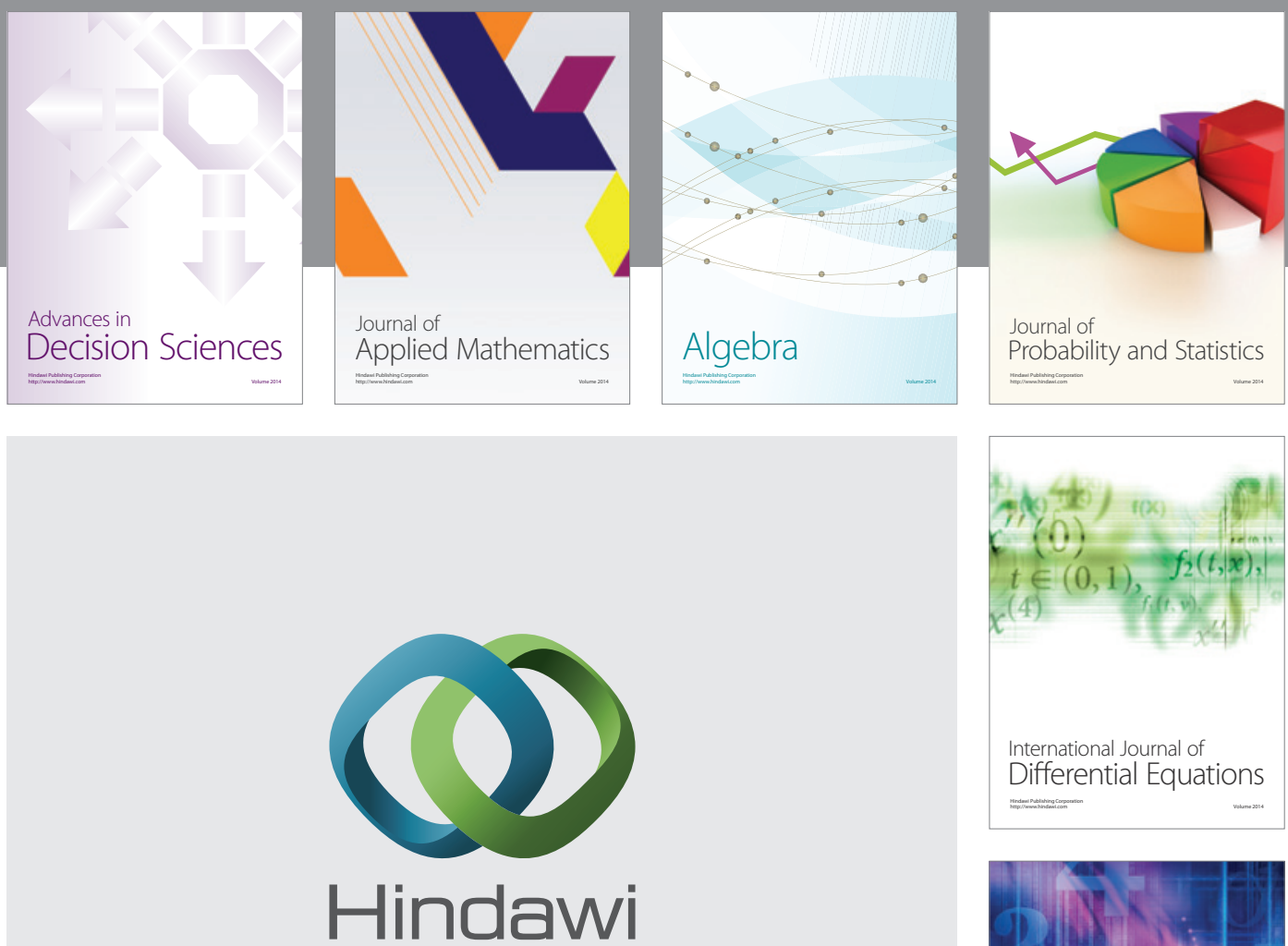

Submit your manuscripts at http://www.hindawi.com
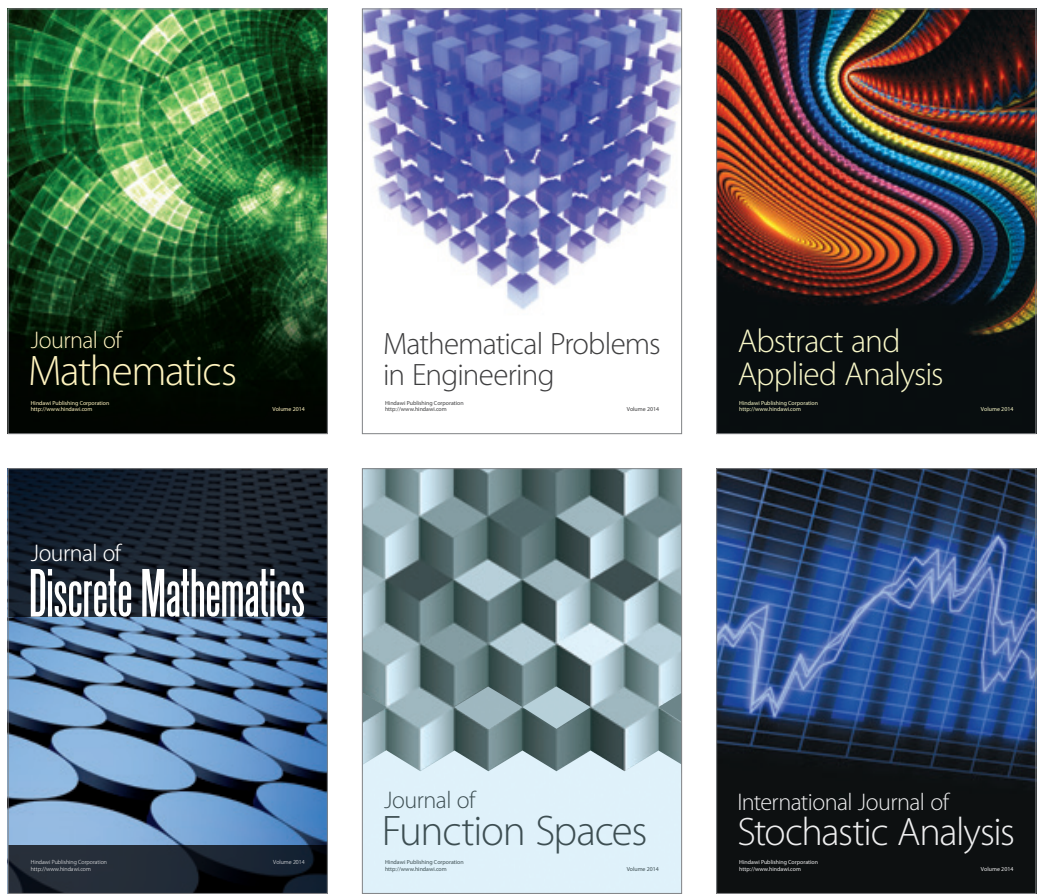

Journal of

Function Spaces

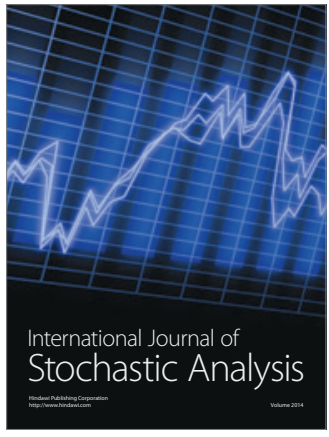

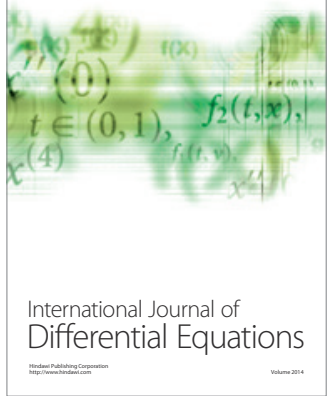
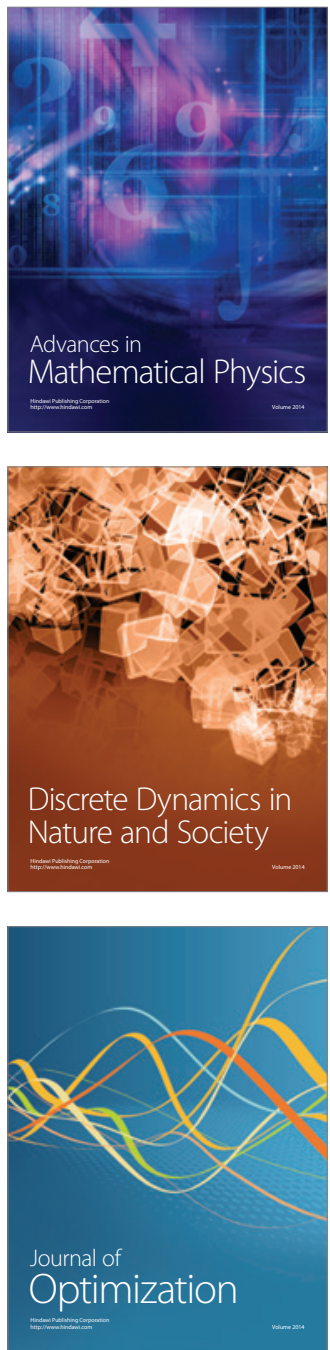